\title{
The influence of vascular endothelial growth factor-A and matrix metalloproteinase-2 and -9 in angiogenesis, metastasis, and prognosis of endometrial cancer
}

\author{
This article was published in the following Dove Press journal: \\ OncoTargets and Therapy \\ 19 September 2017 \\ Number of times this article has been viewed
}

\author{
Anna M Mahecha \\ Hongbo Wang \\ Department of Obstetrics and \\ Gynecology, Union Hospital, Tongji \\ Medical College, Huazhong University \\ of Science and Technology, Wuhan \\ 430022, China
}

\begin{abstract}
Angiogenesis (the growth of new blood vessels) is essential in most of the body's physiological processes, such as in the normal functioning of the endometrium during and after the menstrual cycle. Vascular endothelial growth factor (VEGF) and matrix metalloproteinase (MMP) are the mostly expressed angiogenic factors, especially, during the process of endometrial degeneration and remodeling. In carcinogenesis, tumor hypoxia-induced factors, through the process of "angiogenic switch", stimulate the production of angiogenic factors, particularly VEGF and MMP. Subsequently, these angiogenic factors are associated with degradation, differentiation, proliferation, and migration of vascular endothelial cells, enhancing the formation of new blood vessels to supply the tumor with oxygen and nutrients. This process is equally significant for tumor development and metastasis. Hence, like in other cancers, the overexpression of MMP and VEGF in endometrial cancer (EC) seems to play a significant role in its tumorigenesis and metastasis. This research will discuss the influence of MMP and VEGF on angiogenesis, metastasis, and the prognosis of EC as well as the clinical importance of the factors in the diagnosis of EC.
\end{abstract}

Keywords: angiogenic switch, angiogenic factors, endometrioid endometrial carcinoma, microvascular density

\section{Introduction}

Angiogenesis (ie, growth of new blood vessels) is vital for several physiological processes including wound healing and tissue remodeling in the case of ischemic tissue diseases. ${ }^{1,2}$ It is also crucial for embryo implantation and post-menstruation endometrial repair. ${ }^{3}$ Angiogenesis has also been associated with disorders such as diabetic retinopathy. ${ }^{4,5}$ Recently, several angiogenic factors have been studied, which include vascular endothelial growth factor (VEGF)-A, -B, -C, and -D and their receptors (VEGFR-1, VEGFR-2, and VEGFR-3), placental growth factor (PLGF), matrix metalloproteinase (MMP), platelets-derived growth factor (PDGF), fibroblast growth factor (FGF), tumor growth factor (TGF), and angiopoietins. VEGF-A has been associated with the proliferation, differentiation, degradation, and migration of endothelial cells. Consequently, this leads to the formation of new tubes in the extracellular matrix which is necessary for new vessel formation. ${ }^{6}$ Under normal physiological processes, most of these factors are harmless; however, aberrations during angiogenesis may enhance tumor development.
Correspondence: Hongbo Wang Gynecology, Union Hospital, Tongi Medical College, Huazhong University of Science and Technology, No I277, Jiefang Avenue, Jiangan District, Wuhan 430022, China

Tel/fax +86278572630 I

Email whbdf14@yahoo.com 
In some types of cancer such as colorectal cancer, VEGFassociated angiogenesis seems to play a major role contributing to factors associated with unfavorable prognosis. ${ }^{7}$ However, in other types of cancers, the role of angiogenesis in carcinogenesis and cancer progression is not well understood. This fact has led most physicians and researchers not to conclusively label angiogenesis as an independent factor in the diagnosis and prognosis of these cancers.

Endometrial cancer (EC) starts in the endometrium (the inner lining of the uterus). There are two known clinical pathological variants of EC - Type I and Type II. The most common variant of $\mathrm{EC}$ is endometrioid type endometrial carcinoma (EEC), which falls under Type I, and it accounts for about $80 \%-90 \%$ of all ECs. This type of cancer is estrogen dependent and is associated with endometrial hyperplasia, resulted from excessive unopposed estrogen secretion. It mostly affects post-menopausal women of the average age of 60 years. The prognosis of this cancer is good if early detected. In contrast, Type II EC is non-estrogen dependent and it consists of variants such as uterine serous carcinoma, clear cell carcinoma, and mucinous adenocarcinoma. It mostly affects perimenopause women and typically has poor prognosis. ${ }^{8}$ In the United States alone, about 60,000 new cases of EC have been predicted in 2016, and about 10,000 women would die of the disease. ${ }^{9}$

The purpose of this review is to evaluate the clinical significance of angiogenic markers, specifically VEGF-A and MMP-2/MMP-9, and their related influence in predicting metastasis and prognosis of the patients with EC. Furthermore, we will research whether these markers can be applied as diagnostic markers and in angiogenic inhibition-based therapy for treatment of this deadly disease.

\section{Overview of angiogenesis in cancer}

The essential role of angiogenesis in tumor growth was allegedly first proposed in 1971 by Judah Folkman. Tumor cells are those that have lost their ability to divide in a controlled fashion. Moreover, in order to grow, they need constant nourishment. According to Naumov et $\mathrm{al}^{12}$ and Folkman, ${ }^{13}$ the ability of tumors to progress from a non-angiogenic to an angiogenic phenotype is central to the progression of cancer and is termed the "angiogenic switch". ${ }^{10}$ This phenomenon is a prerequisite for tumor growth and metastasis. Tumor cells can migrate from their primary site to a new site through direct metastasis, blood vessels, or lymphatic system. However, if these tumors are of a microscopic size and angiogenic factors are inhibited, they may remain dormant without further growth. But if the inhibitor is suppressed, they resume rapid growth. Tumors that grow $>1-2 \mathrm{~mm}$ are angiogenic dependent. Angiogenesis facilitates the escape of cancer cells through the new blood vessels and starts to form a new colony of cancers called metastasis. Tumors that are located in avascular areas (blood vessels scarce areas) mostly remain dormant for longer periods compared to those located in a well-vascularized area; the former is associated with late symptoms and late metastasis compared to the latter. ${ }^{10-13}$ Arguably, Gelao et a ${ }^{14}$ found that the tendency of tumor dormancy is multifactorial and does not depend entirely on angiogenesis.

\section{Vascular endothelial growth factor and matrix metalloproteinase in the endometrium and cancers in general}

VEGF is a member of six structurally related proteins which include VEGF-B, -C, -D, and the PLGF. VEGF-A was the earliest to be found and the most studied of the members. ${ }^{15}$ Originally known as vascular permeability factor (VPF), it is a prime angiogenic stimulus for vascular permeability based on its capability to bring on vascular leakage. ${ }^{16,17}$ Aberration of this factor may contribute to the pathology of the endometrium-like dysfunctional uterine bleeding. ${ }^{18}$ In line with the process of endometrial remodeling, the release of VEGF is thought to be initiated by the hypoxia or ischemia of tissues. When a tissue is hypoxic, the hypoxia-induced factors are stimulated through a number of pathways to signal the release of different growth factors including VEGF, which then leads to the degradation of the extracellular matrix by the MMP. ${ }^{19}$

In adults, angiogenesis and biological effects of VEGF, which induce endothelial cell proliferation and migration to form new vessels, are mediated by two tyrosine kinase receptors, VEGF receptor-1 and -2 (VEGFR-1 and VEGFR-2). Of the two tyrosine kinases, VEGFR-2 is thought to be more prominent and more involved in the angiogenic processes than VEGFR-1. VEGF can also bind to a lymphangiogenesisrelated tyrosine kinase VEGFR-3. ${ }^{16}$ According to Lucas et $\mathrm{al}^{20}$ VEGF expression is restricted not only to vascular endothelial blood cells but it can also be expressed in other cells like macrophages.

MMPs, a family of zinc-dependent endoproteinases, are key players in the degradation of extracellular matrix and basement membranes, as well as in vascularization and cell migration..$^{21,22}$ There are 24 estimated types of MMP genes and 23 types of MMP proteins known so far which have diverse physiological and pathological functions. ${ }^{23-25}$ The physiological functions of MMPs are controlled by the 
proteins called tissue inhibitors of the matrix metalloproteinase (TIMPs), which are also expressed in tumor sites. ${ }^{26}$ MMP-2 and MMP-9 are also known as the gelatinases (gelatinases $\mathrm{A}$ and $\mathrm{B}$, respectively).

The angiogenic markers MMP and VEGF are considered to be involved in the remodeling of endometrium after menstruation. Goffin et al using normal endometrial tissues of healthy women with regular menstrual cycles found that the MMP-9 mRNA was highly expressed during the menstrual phase while MMP-2 mRNA remained consistent throughout the whole cycle. ${ }^{27}$ In another study, Skinner et al using the tissue samples of women with normal, regular menstrual cycle reported that MMP-9 protein was immunolocalized to glandular epithelial cells throughout the menstrual cycle with maximal intensity in the glandular epithelium. ${ }^{28}$ These constant cyclic changes in the endometrium, degeneration of the superficial layer, and reconstruction of a new one are all associated with angiogenesis and neovascularization.

In patients with anovulatory dysfunctional uterine bleeding, Shan et al found that VEGF, MMP-2, and MMP-9 were equally overexpressed, and silencing VEGF significantly reduced the expression of MMP- 2 and MMP- $9 .{ }^{29}$ In the case of implantation, MMP activity is reduced and VEGF activity is increased to prepare the endometrium for placentation. Therefore, the two angiogenic markers work hand in hand to ensure the normal functioning of the endometrium during menstrual cycle and implantation. ${ }^{30}$

VEGF and MMP, simultaneously, have been found to have significant impacts on either tumor invasion, metastasis, advanced tumor stage, or adverse prognosis. For example, using thyroid cancer cells, Jia et $\mathrm{al}^{31}$ studied the angiogenesis-related protein S100A4 and discovered that its downregulation resulted also in the downregulation of VEGF together with MMP-9. Additionally, the knockdown of both VEGF and MMP-9 resulted in significant inhibition of the thyroid cells invasion, metastasis, and angiogenesis, respectively. Moreover, Zheng et $\mathrm{al}^{32}$ by using 249 gastric cancer tissues found that MMP-2, MMP-9, and VEGF were positively correlated with tumor size, depth of invasion, lymphatic and venous invasion, lymph node metastasis, and microvascular density (MVD) of gastric carcinoma. In addition, VEGF expression was positively linked with levels of MMP-2 and MMP-9. Furthermore, VEGF, MMP-2, and MMP-9 were also found to be significantly related to recurrence of hepatocellular carcinoma in the patients who underwent liver transplant. ${ }^{33}$

In gynecological cancers, for example in ovarian cancer, the expression of VEGF was closely related to the expression of MMP-2 which in turn resulted in the increased invasion of the epithelial ovarian cancer cells in vitro and in vivo. ${ }^{34,35}$ In addition, in uterine cervical cancer, MMP-2 and VEGF were found to be correlated with adverse prognosis in young women. ${ }^{36}$

The mechanism resulting to tumor metastasis has been elucidated using "angiogenic switch" phenomenon. Figure 1 summarizes the process of angiogenic switch and metastasis as previously described by Folkman. ${ }^{13}$

The overexpression of VEGF and its relationship with prognosis and metastasis have been widely studied in different types of solid cancers. For instance, VEGF angiogenesis was found to be an independent prognostic indicator in breast cancer and was associated with poor prognosis and

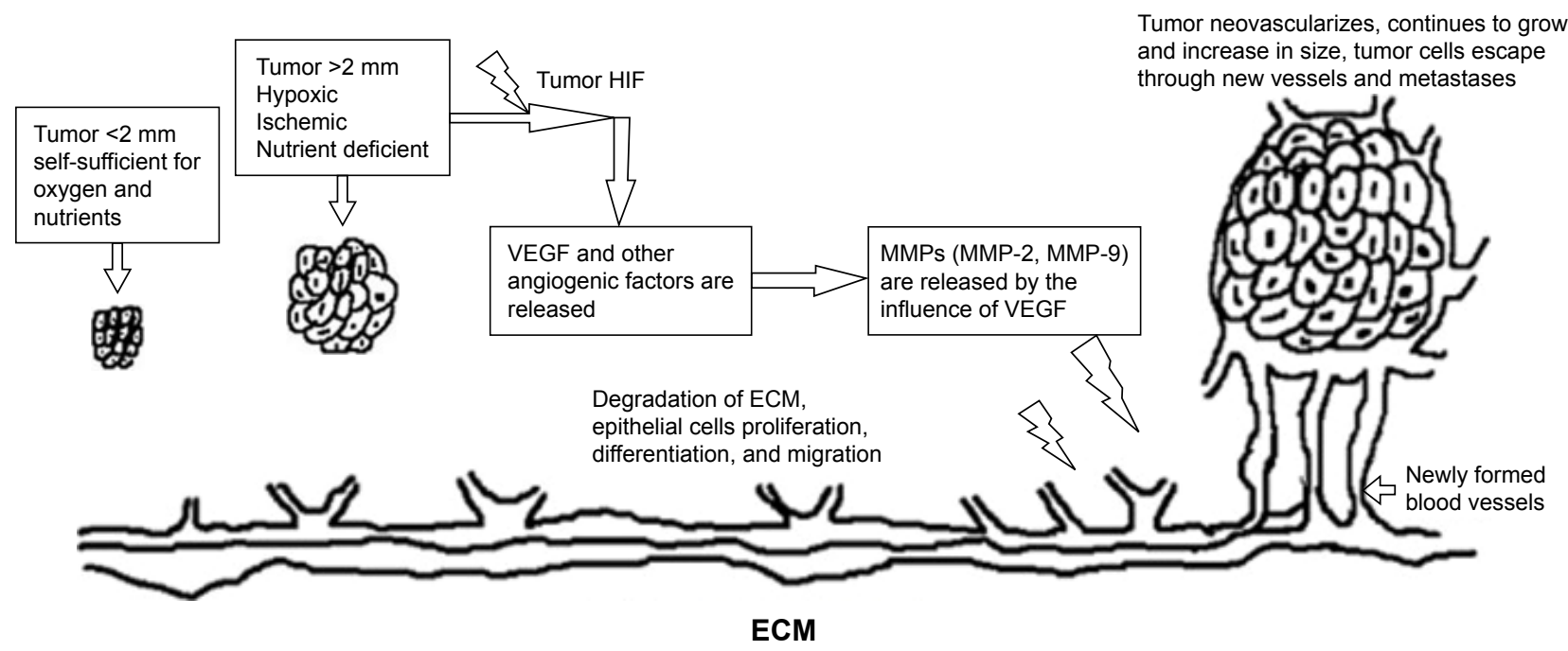

Figure I Influence of VEGF-A in EC.

Abbreviations: EC, endometrial cancer; ECM, extracellular matrix; HIF, hypoxia-induced factor; VEGF-A, vascular endothelial growth factor-A. 
metastasis. ${ }^{37}$ In non-small cell lung carcinoma, Bremnes et $\mathrm{al}^{38}$ found that VEGF was found to be associated with poor prognosis, disease aggressiveness, and poor survival. In ovarian cancer, ${ }^{39}$ cervical cancer, ${ }^{40}$ colon cancers, and melanomas, ${ }^{41,42}$ the overexpression of serum VEGF was either associated with lower disease-free survival (DFS), metastasis, or poor disease progression. According to the study of Dai et al, Piastowska-Ciesielska et al, and Yang et $\mathrm{al},{ }^{43-45}$ it is evident that VEGF is overexpressed in endometrial malignancies, and it is thought to be an important angiogenic marker in the carcinogenesis of this type of cancer.

The mechanism in which these tumors induce signals for VEGF expression is said to be due to tumor hypoxia which then signals the production of cellular hypoxia-inducible factor (HIF). According to North et al, ${ }^{46}$ this factor initiates the overproduction of VEGF and starts the angiogenic process through the tyrosine kinase pathway which stimulates endothelial cell proliferation, migration, and the formation of new vessels to supply oxygen and nutrients to the tumor which facilitate its growth and metastasis.

Saarelainen et al, while assessing the prognostic significance of VEGF in EC from preoperative sera of 98 women presenting with $\mathrm{EC}$, reported that the serum concentrations of VEGF and its receptors were assessed by enzyme-linked immunosorbent assay (ELISA). The results were correlated to the presence of deep $(>50 \%)$ myometrial invasion and metastasis. The serum concentration of VEGF was higher in the group with metastasis than in the group without metastasis (median [range]: $743 \mathrm{pg} / \mathrm{mL}$ [546-1,183 pg/mL] vs $383 \mathrm{pg} / \mathrm{mL}$ [31-1,524 pg/mL]) and hence VEGF was related to poor prognosis and metastasis. ${ }^{47}$ In addition, Topolovec et $\mathrm{al}^{48}$ found that the overexpression of VEGF was also associated with deep myometrial invasion, advanced histological stage, and grade of differentiation.

Contrary to the above findings, Soufla et $\mathrm{al}^{49}$ found that VEGF expression status (whether high or low) corresponded only with the malignant transformation of the endometrium but did not correlate with either tumor stage, myometrial invasion, or grade of differentiation; therefore, its expression was not a significant indicator of prognosis. Dobrzycka et $\mathrm{al}^{52}$ went further to investigate the expression of VEGF in the two pathological types of EC and found that VEGF expression was associated with advanced stage in Type II but not in Type I EC and was not found to be an independent prognostic factor or corresponding with DFS. ${ }^{50,51}$ In 2010, the same authors evaluated the prognostic significance of VEGF using 84 EEC tissue samples; their results showed that out of 84 cancer tissue samples, strong positive expression of VEGF was observed in $35(42 \%)$ tumors. There was a significant correlation between histological grade, clinical stage, and VEGF overexpression. The 5-year DFS of patients with VEGF overexpression was significantly lower than that of those with a weakly positive or negative tumor. ${ }^{52}$ Furthermore, Wang et al found that serum VEGF overexpression in ECs was significantly higher in late stage EC than in early stage EC and it increased significantly from well differentiated to poorly differentiated tumors. ${ }^{53}$ Moreover, Topolovec et $\mathrm{al}^{48}$ and Yang et $\mathrm{al}^{45}$ in two different studies also found that elevated VEGF expression was significantly associated with either deep myometrial invasion, poor differentiation and histologic type, or lymph node metastasis in patients with EC.

\section{Influence of matrix metalloproteinase-2 and matrix metalloproteinase- 9 in endometrial cancer}

Association of MMPs with carcinogenesis has been studied in different types of solid cancers such as colon cancers, ${ }^{54}$ ovarian cancer, ${ }^{55}$ and breast cancer. ${ }^{56}$ These studies found MMPs to correlate either with cancer progression, disease aggressiveness, metastasis, and poor disease prognosis or with poor DFS. This part of the review will discuss the influence of MMP-2 and MMP-9 on metastasis and the overall prognosis of EC.

There is evidence that MMP-2 and MMP-9 are overexpressed in EC, especially in EEC; however, their expression varies according to the grade of differentiation or histological grades. ${ }^{57-60}$ There are scarce studies on how these gelatinases influence prognosis and metastasis of EC. However, the limited data already available provide insight into how important gelatinases are in the pathogenesis of EC. Li et al ${ }^{61}$ examined the correlation of MMP-2 expression with the clinical characteristics and prognosis of the endometrial adenocarcinoma in patients aged 32-80 years in 81 paraffinembedded samples. They found that the overexpression of MMP-2 was negatively correlated with tumor differentiation and prognosis of endometrial adenocarcinoma.

In determining the prognostic significance of MMP-2 in EC, Honkavuori-Toivola et al used 225 tissue samples of patients with EEC; in their results, they found MMP-2 negative patients had a significantly higher 5 -year survival rate compared to MMP-2 positive patients. Also relative risk of death in the latter group was 4.7 times higher compared to the former group of patients. ${ }^{62}$ Additionally, Yu et al used 128 tissue samples from Chinese women with EC to study the MMP-9 expression and its correlation with survival and clinicopathological features. Their results showed that there 
was a significantly higher expression of MMP-9 in the tissues; this overexpression was correlated only with lymph node metastasis, histological grade, and myometrial invasion but was not correlated with patient survival. ${ }^{63}$ However, Bogusiewicz et al, in studying the activities of MMP-2 and MMP-9 in EC, used 28 samples of EC and 15 samples of normal endometrium. They observed significantly higher activity of MMP-9 in EC samples compared to normal endometrium, which was related to EC progression, however there was no changes of activity for MMP-2 in EC compared to the normal endometrium. These same results were found with Yilmaz et al. ${ }^{64,65}$

In their experiment to further explore whether the stromal MMP-2 and MMP-9 or epithelial MMP-2 and MMP-9 were more significant in determining prognosis in EC patients, Puljiz et al found that in univariate analysis stromal MMP-2 expression was identified as one of the significant determinants of EC recurrence while epithelial MMP-2 expression and epithelial and stromal MMP-9 expressions were not. During multivariate analysis, strong staining of stromal MMP-2 increased the risk of EC recurrence in a subgroup of patients aged $\geq 63.6$ years with endometrioid adenocarcinoma and papillary serous carcinoma, and all FIGO (International Federation of Gynecology and Obstetrics revised version of 2009) stage 1 diseases. ${ }^{66}$ The study by Karahan et al supported MMP-2 and MMP-9 to significantly correlate with myometrial, vascular, and lymphatic invasions. ${ }^{67}$ Contrarily, authors like Aglund et al found that the protein overexpression of both MMP-2 and MMP-9 was associated with poor survival and histological grades, and only MMP-9 correlated with clinical stage of EC and not MMP-2. Furthermore, the overexpression of both proteins was not associated with any type of invasion. ${ }^{68}$ However, Graesslin et al in two different studies ${ }^{69,70}$ revealed that only MMP-2 correlated with histological grade and was significant as a prognostic marker for local and distal metastases in endometrial carcinoma.

\section{Concluding remarks for VEGF-A}

The prognostic and metastatic effects of VEGF have been associated with the value/number of new blood vessels formed, which is referred to as MVD. This means that the higher the value of MVD, the higher is the likelihood of deep myometrial invasion, vascular metastasis, poor grade, poor prognosis, and consequently, less DFS. According to the study by Horrée et $\mathrm{al}^{71}$ and the above theory, it seems that the more the new blood vessels are formed the higher are the chances of tumor metastasis and poor prognosis.
There is a positive correlation between the overexpression of VEGF and MVD with either increased deep myometrial invasion, poorly differentiated tumors, histological-type FIGO stage, lymphovascular infiltration, or lymph node involvement. ${ }^{48,72,73}$

In this review, the overexpression of VEGF seems to play a critical role in determining prognosis and metastasis and hence overall survival in EC. It is well established that the uterus is a hormonally controlled organ; therefore, in order to widely grasp the extent to which this angiogenic factor affects prognosis and metastasis of EC, the influence of hormones such as estrogen and progesterone in relation to VEGF expression cannot be neglected. ${ }^{74}$ In addition, since the introduction of the use of the angiogenesis inhibitors for VEGF, such as bevacizumab, as a single agent or in combination with other agents like chemotherapy drugs for the treatment of EC, many patients have benefited in spite of the claimed major side effects, especially those of cardiovascular and gastrointestinal systems. ${ }^{75,76}$ In view of the above, serum levels of VEGF should be considered before, during, and after treatment and as a routine checkup for EC patients at a certain interval. This is significant in comparing the patients' disease progression and evaluating treatment efficiency.

\section{Concluding remarks for MMP-2/MMP-9}

In conclusion, both MMP-2 and MMP-9 seem to play significant independent roles in tumor/cancer development, thereby being involved one way or the other as a prognosis and metastasis indicator. However, in EC, there is still a controversy involving which of the MMPs are more involved in metastasis, advanced tumor grade, histological grade, depth of invasion, and poor prognosis. Moreover, most of the cited authors pointed out that the enhanced expression of MMP-2 is more associated with disease progression and aggressiveness and more unfavorable prognosis compared to that of MMP-9 in EC.

In addition, studies concerning the influence of these angiogenic markers on EC variants, histological grade, and the stage are greatly needed as they will give a deeper understanding of their involvement in the progression of EC. However, further studies will determine whether stromal or epithelial MMP-2/MMP-9 has much significance in carcinogenesis of EC. The above concerns may widen the knowledge in the field of metalloproteinase-based therapy which can help reduce the mortality and morbidity and prolong the survival rate in endometrial carcinoma patients. 
Finally, understanding the connected pathways that associate VEGFs and MMPs in carcinogenesis and their contributing factors of their enhanced expression in either serum or cancer tissues, and their association with other genes that are involved in apoptotic, migration, and differentiation of cells, may contribute significantly in the establishment of angiogenic-based inhibition therapy for EC.

\section{Disclosure}

The authors report no conflicts of interest in this work.

\section{References}

1. Polverini PJ. Angiogenesis and wound healing: basic discoveries, clinical implications, and therapeutic opportunities. Endod Top. 2011; 24(1):130-145.

2. DiPietro LA. Angiogenesis and scar formation in healing wounds. Curr Opin Rheumatol. 2013;25(1):87-91.

3. Demir R, Yaba A, Huppertz B. Vasculogenesis and angiogenesis in the endometrium during menstrual cycle and implantation. Acta Histochem. 2010;112(3):203-214.

4. Abu El-Asrar AM, Nawaz MI, Kangave D, Siddiquei MM, Ola MS, Opdenakker G. Angiogenesis regulatory factors in the vitreous from patients with proliferative diabetic retinopathy. Acta Diabetol. 2013; 50(4):545-551.

5. Zhou J, Wang S, Xia X. Role of intravitreal inflammatory cytokines and angiogenic factors in proliferative diabetic retinopathy. Curr Eye Res. 2012;37(5):416-420.

6. Tammela T, Enholm B, Alitalo K, Paavonen K. The biology of vascular endothelial growth factors. Cardiovasc Res. 2005;65(3):550-563.

7. Wang Y, Yao X, Ge J, Hu F, Zhao Y. Can vascular endothelial growth factor and microvessel density be used as prognostic biomarkers for colorectal cancer? A systematic review and meta-analysis. ScientificWorldJournal. 2014;2014:102736.

8. Bokhman JV. Two pathogenetic types of endometrial carcinoma. Gynecol Oncol. 1983;15(1):10-17.

9. Cancer.org [homepage on the Internet]. 2017 American Cancer Society, Inc. Available from: http://www.cancer.org/cancer/endometrialcancer/ detailedguide/endometrial-uterine-cancer-key-statistics. Accessed 4 January 2017.

10. Naumov GN, Akslen LA, Folkman J. Role of angiogenesis in human tumor dormancy: animal models of the angiogenic switch. Cell Cycle. 2006;5(16):1779-1787.

11. Naumov GN, Folkman J, Straume O. Tumor dormancy due to failure of angiogenesis: role of the microenvironment. Clin Exp Metastasis. 2009; 26(1):51-60.

12. Naumov GN, Folkman J, Straume O, Akslen LA. Tumor-vascular interactions and tumor dormancy. Apmis. 2008;116(7-8):569-585.

13. Folkman J. Role of angiogenesis in tumor growth and metastasis. Semin Oncol. 2002;(6 Suppl 16):15-18.

14. Gelao L, Criscitiello C, Fumagalli L, et al. Tumour dormancy and clinical implications in breast cancer. Ecancermedicalscience. 2013;7:320.

15. Yamazaki Y, Morita T. Molecular and functional diversity of vascular endothelial growth factors. Mol Divers. 2006;10(4):515-527.

16. Ferrara N, Gerber HP, LeCouter J. The biology of VEGF and its receptors. Nat Med. 2003;9(6):669-676.

17. Lai TH, Vlahos N, Shih IM, Zhao Y. Expression patterns of VEGF and Flk-1 in human endometrium during the menstrual cycle. J Reprod Infertil. 2015;16(1):3-9.

18. Zhang X, Qi C, Lin J. Enhanced expressions of matrix metalloproteinase (MMP)-2 and -9 and vascular endothelial growth factors (VEGF) and increased microvascular density in the endometrial hyperplasia of women with anovulatory dysfunctional uterine bleeding. Fertil Steril. 2010;93(7):2362-2367.
19. Christoffersson G, Vågesjö E, Vandooren J, etal. VEGF-A recruits a proangiogenic MMP-9-delivering neutrophil subset that induces angiogenesis in transplanted hypoxic tissue. Blood. 2012;120(23):4653-4662.

20. Lucas T, Waisman A, Ranjan R, et al. Differential roles of macrophages in diverse phases of skin repair. J Immunol. 2010;184(7):3964-3977.

21. Chang C, Werb Z. The many faces of metalloproteases: cell growth, invasion, angiogenesis and metastasis. Trends Cell Biol. 2001;11(11): S37-S43.

22. Zítka O, Kukacka J, Krizkov S, et al. Matrix metalloproteinases. Curr Med Chem. 2010;17(31):3751-3768.

23. Hadler-Olsen E, Fadnes B, Sylte I, Uhlin-Hansen L, Winberg JO. Regulation of matrix metalloproteinase activity in health and disease. FEBS J. 2011;278(1):28-45.

24. Hadler-Olsen E, Winberg JO, Uhlin-Hansen L. Matrix metalloproteinases in cancer: their value as diagnostic and prognostic markers and therapeutic targets. Tumor Biol. 2013;34(4):2041-2051.

25. Klein T, Bischoff R. Physiology and pathophysiology of matrix metalloproteases. Amino Acids. 2011;41(2):271-290.

26. Deryugina EI, Quigley JP. Matrix metalloproteinases and tumor metastasis. Cancer Metastasis Rev. 2006;25(1):9-34.

27. Goffin F, Munaut C, Frankenne F, et al. Expression pattern of metalloproteinases and tissue inhibitors of matrix-metalloproteinases in cycling human endometrium. Biol Reprod. 2003;69(3):976-984.

28. Skinner JL, Riley SC, Gebbie AE, Glasier AF, Critchley HO. Regulation of matrix metalloproteinase-9 in endometrium during the menstrual cycle and following administration of intrauterine levonorgestrel. Human Reprod. 1999;14(3):793-799.

29. Shan B, Li W, Yang SY, Li ZR. Estrogen up-regulates MMP2/9 expression in endometrial epithelial cell via VEGF-ERK1/2 pathway. Asian Pac J Trop Med. 2013;6(10):826-830.

30. Furukawa Y, Kawano Y, Fukuda J, Matsumoto H, Narahara H. The production of vascular endothelial growth factor and metalloproteinase via protease-activated receptor in human endometrial stromal cells. Fertil Steril. 2009;91(2):535-541.

31. Jia W, Gao XJ, Zhang ZD, Yang ZX, Zhang G. S100A4 silencing suppresses proliferation, angiogenesis and invasion of thyroid cancer cells through downregulation of MMP-9 and VEGF. Eur Rev Med Pharmacol Sci. 2013;17(11):1495-1508.

32. Zheng H, Takahashi H, Murai Y, et al. Expressions of MMP-2, MMP-9 and VEGF are closely linked to growth, invasion, metastasis and angiogenesis of gastric carcinoma. Anticancer Res. 2006;26(5A): 3579-3583.

33. Zhang Q, Chen X, Zhou J, et al. CD147, MMP-2, MMP-9 and MVDCD34 are significant predictors of recurrence after liver transplantation in hepatocellular carcinoma patients. Cancer Biol Ther. 2006;5(7): 808-814.

34. Zhang A, Meng L, Wang Q, et al. Enhanced in vitro invasiveness of ovarian cancer cells through up-regulation of VEGF and induction of MMP-2. Oncol Rep. 2006;15(4):831-836.

35. Belotti D, Calcagno C, Garofalo A, et al. Vascular endothelial growth factor stimulates organ-specific host matrix metalloproteinase-9 expression and ovarian cancer invasion. Mol Cancer Rese. 2008;6(4):525-534.

36. Noriyuki M, Sumi T, Zhi X, et al. Vascular endothelial growth factor, matrix metalloproteinases, and cyclooxygenase- 2 influence prognosis of uterine cervical cancer in young women. Int J Oncol. 2007;31(3): 531-536.

37. Ali EM, Sheta M, El Mohsen MA. Elevated serum and tissue VEGF associated with poor outcome in breast cancer patients. Alexandria $J$ Med. 2011;47(3):217-224.

38. Bremnes RM, Camps C, Sirera R. Angiogenesis in non-small cell lung cancer: the prognostic impact of neoangiogenesis and the cytokines VEGF and bFGF in tumours and blood. Lung Cancer. 2006;51(2):143-158.

39. Bandiera E, Franceschini R, Specchia C, et al. Prognostic significance of vascular endothelial growth factor serum determination in women with ovarian cancer. ISRN Obstet Gynecol. 2012;2012:245756.

40. Du K, Gong HY, Gong ZM. Influence of serum VEGF levels on therapeutic outcome and diagnosis/prognostic value in patients with cervical cancer. Asian Pac J Cancer Prev. 2013;15(20):8793-8796. 
41. Crosby MB, Yang H, Gao W, Zhang L, Grossniklaus HE. Serum vascular endothelial growth factor (VEGF) levels correlate with number and location of micrometastases in a murine model of uveal melanoma. Br J Ophthalmol. 2011;95(1):112-117.

42. Rajabi P, Neshat A, Mokhtari M, Rajabi MA, Eftekhari M, Tavakkoli P. The role of VEGF in melanoma progression. J Res Med Sci. 2012; 17(6):534-539.

43. Dai H, Zhao S, Xu L, Chen A, Dai S. Expression of Efp, VEGF and bFGF in normal, hyperplastic and malignant endometrial tissue. Oncol Rep. 2010;23(3):795-799.

44. Piastowska-Ciesielska AW, Płuciennik E, Wójcik-Krowiranda K, Bieńkiewicz A, Bednarek A, Ochędalski T. Analysis of the expression of angiotensin II type 1 receptor and VEGF in endometrial adenocarcinoma with different clinicopathological characteristics. Tumor Biol. 2012;33(3):767-774.

45. Yang Y, Liu H, Li W. [Expression of Mta-1 and VEGF and their correlation in the endometrial cancer]. Xi Bao Yu Fen Zi Mian Yi Xue Za Zhi. 2010;26(7):682-684. Chinese.

46. North S, Moenner M, Bikfalvi A. Recent developments in the regulation of the angiogenic switch by cellular stress factors in tumors. Cancer Lett. 2005;218(1):1-14.

47. Saarelainen SK, Staff S, Peltonen N, et al. Endoglin, VEGF, and its receptors in predicting metastases in endometrial carcinoma. Tumor Biol. 2014;35(5):4651-4657.

48. Topolovec Z, Coručić A, Babić D, et al. Vascular endothelial growth factor and intratumoral microvessel density as prognostic factors in endometrial cancer. Coll Antropol. 2010;34(2):447-453.

49. Soufla G, Sifakis S, Porichis F, Spandidos DA. Prognostic value of tgfb1 protein in endometrioid adenocarcinoma. Eur J Clin Invest. 2013;43(1):79-90.

50. Dobrzycka B, Mackowiak-Matejczyk B, Kinalski M, Terlikowski SJ. Pretreatment serum levels of bFGF and VEGF and its clinical significance in endometrial carcinoma. Gynecol Oncol. 2013;128(3): 454-460.

51. Dobrzycka B, Terlikowski SJ, Kowalczuk O, Kulikowski M, Niklinski J. Serum levels of VEGF and VEGF-C in patients with endometrial cancer. Eur Cytokine Netw. 2011;22(1):45-51.

52. Dobrzycka B, Terlikowski S, Kwiatkowski M, Garbowicz M, Kinalski M, Chyczewski L. Prognostic significance of VEGF and its receptors in endometrioid endometrial cancer. Ginekol Pol. 2010;81(6): $422-425$.

53. Wang X, Pan Z, Li A, Zhu M. [Study on the correlation of Xinjiang endometrial tumor and vascular endothelial growth factor]. Zhonghua Shi Yan He Lin Chuang Bing Du Xue Za Zhi. 2010;24(2):98-100. Chinese.

54. Park KS, Kim SJ, Kim KH, Kim JC. Clinical characteristics of TIMP2, MMP2, and MMP9 gene polymorphisms in colorectal cancer. J Gastroenterol Hepatol. 2011;26(2):391-397.

55. Hu X, Li D, Zhang W, Zhou J, Tang B, Li L. Matrix metalloproteinase-9 expression correlates with prognosis and involved in ovarian cancer cell invasion. Arch Gynecol Obstet. 2012;286(6):1537-1543.

56. Min KW, Kim DH, Do SI, et al. Expression patterns of stromal MMP-2 and tumoural MMP-2 and -9 are significant prognostic factors in invasive ductal carcinoma of the breast. Apmis. 2014;122(12): 1196-1206.

57. Grybos A, Bar J. The relationships between the immunoexpression of KAI1, MMP-2, MMP-9 and steroid receptors expression in endometrial cancer. Folia Histochem Cytobiol. 2014;52(3):187-194.

58. Planagumà J, Liljeström M, Alameda F, et al. Matrix metalloproteinase-2 and matrix metalloproteinase-9 codistribute with transcription factors RUNX1/AML1 and ETV5/ERM at the invasive front of endometrial and ovarian carcinoma. Hum Pathol. 2011;42(1):57-67.
59. Wang X, Chen X. [Expression and significance of Twist1 and MMP-2 in endometrial endometrioid adenocarcinoma]. Zhonghua Zhong Liu Za Zhi. 2012;34(8):588-591. Chinese.

60. Weigel MT, Krämer J, Schem C, et al. Differential expression of MMP-2, MMP-9 and PCNA in endometriosis and endometrial carcinoma. Eur J Obstet Gynecol Reprod Biol. 2012;160(1):74-78.

61. Li S, Shen X, Yang Z, et al. [Clinical significance of MMP2 overexpression in endometrial adenocarcinoma]. Nan Fang Yi Ke Da Xue Bao. 2014;34(3):423-425. Chinese.

62. Honkavuori-Toivola M, Santala M, Soini Y, Turpeenniemi-Hujanen T, Talvensaari-Mattila A. Combination of strong MMP-2 and weak TIMP-2 immunostainings is a significant prognostic factor in endometrial carcinoma. Dis Markers. 2013;35(4):261-266.

63. Yu F, Jiang Q, Zhou Y, et al. Abnormal expression of matrix metalloproteinase-9 (MMP9) correlates with clinical course in Chinese patients with endometrial cancer. Dis Markers. 2012;32(5):321-327.

64. Bogusiewicz M, Stryjecka-Zimmer M, Rechberger T. [Activity of matrix metalloproteinases -2 and -9 (MMP-2 and MMP-9) and content of their tissue inhibitors in endometrial cancer-a preliminary study]. Ginekol Pol. 2007;78(5):366-372. Polish.

65. Yilmaz E, Koyuncuoglu M, Görken İB, et al. Expression of matrix metalloproteinase-2 and survivin in endometrioid and nonendometrioid endometrial cancers and clinicopathologic significance. J Gynecol Oncol. 2011;22(2):89-96.

66. Puljiz M, Puljiz Z, Vucemilo T, et al. Prognostic significance of matrix metalloproteinases 2 and 9 in endometrial cancer. Coll Antropol. 2012; 36(4):1367-1372.

67. Karahan N, Güney M, Baspinar S, Oral B, Kapucuoglu N, Mungan T. Expression of gelatinase (MMP-2 and MMP-9) and cyclooxygenase-2 (COX-2) in endometrial carcinoma. Eur J Gynaecol Oncol. 2007; 28(3):184-188.

68. Aglund K, Rauvala M, Puistola U, et al. Gelatinases A and B (MMP-2 and MMP-9) in endometrial cancer - MMP-9 correlates to the grade and the stage. Gynecol Oncol. 2004;94(3):699-704.

69. Graesslin O, Cortez A, Fauvet R, Lorenzato M, Birembaut P, Daraï E. Metalloproteinase-2, -7 and -9 and tissue inhibitor of metalloproteinase-1 and -2 expression in normal, hyperplastic and neoplastic endometrium: a clinical-pathological correlation study. Ann Oncol. 2006; 17(4):637-645.

70. Graesslin O, Cortez A, Uzan C, Birembaut P, Quereux C, Daraï E. Endometrial tumor invasiveness is related to metalloproteinase 2 and tissue inhibitor of metalloproteinase 2 expressions. Int J Gynecol Cancer. 2006;16(5):1911-1917.

71. Horrée N, van Diest PJ, van der Groep P, Sie-Go DM, Heintz AP. Hypoxia and angiogenesis in endometrioid endometrial carcinogenesis. Cell Oncol. 2007;29(3):219-227.

72. Guset G, Costi S, Lazar E, et al. Expression of vascular endothelial growth factor (VEGF) and assessment of microvascular density with CD34 as prognostic markers for endometrial carcinoma. Rom J Morphol Embryol. 2010;51(4):677-682.

73. Wang J, Taylor A, Showeil R, et al. Expression profiling and significance of VEGF-A, VEGFR2, VEGFR3 and related proteins in endometrial carcinoma. Cytokine. 2014;68(2):94-100.

74. Ferrara N, Chen H, Davis-Smyth T, et al. Vascular endothelial growth factor is essential for corpus luteum angiogenesis. Nat Med. 1998; 4(3):336-340.

75. Bogliolo S, Cassani C, Gardella B, et al. Current opinion on bevacizumab on endometrial cancer treatment. Exp Opin Biol Ther. 2015; 15(2):299-307.

76. Aghajanian C, Sill MW, Darcy KM, et al. Phase II trial of bevacizumab in recurrent or persistent endometrial cancer: a gynecologic oncology group study. J Clin Oncol. 2011;29(16):2259-2265. 


\section{Publish your work in this journal}

OncoTargets and Therapy is an international, peer-reviewed, open access journal focusing on the pathological basis of all cancers, potential targets for therapy and treatment protocols employed to improve the management of cancer patients. The journal also focuses on the impact of management programs and new therapeutic agents and protocols on

patient perspectives such as quality of life, adherence and satisfaction. The manuscript management system is completely online and includes a very quick and fair peer-review system, which is all easy to use. Visit http://www.dovepress.com/testimonials.php to read real quotes from published authors.

Submit your manuscript here: http://www.dovepress.com/oncotargets-and-therapy-journal 